\title{
Nu thuismeting van zuurstofsaturatie ineens reguliere huisartsenzorg lijkt te zijn...
}

\author{
Dorien Zwart, Roderick Venekamp, Karin Smit, Geert Jan Geersing, Cor Kalkman, Frans Rutten
}

Thuismeting van zuurstofsaturatie bij COVID-19-patiënten neemt momenteel een vlucht in de huisartsenpraktijk. Het is een praktisch middel om patiënten thuis te monitoren. De validiteit van de saturatiemetingen vormt echter een punt van zorg. Daarnaast verdient wetenschappelijke onderbouwing van de toegevoegde waarde van thuismeting van zuurstofsaturatie meer aandacht. Zeker met het oog op mogelijke klinische vervolgstappen naar substitutie van zorg in de thuisbehandeling van COVID-19-patiënten.

Nieuwe ideeën worden nooit door maar 1 enkel persoon bedacht. Zo verging het ook de praktische gedachte om zuurstofsaturatie bij COVID-19-patiënten thuis te meten. Tijdens de coronacrisis kwam dit idee bij meerdere huisartsen en andere collega's tegelijk op. Daling van zuurstofsaturatie is immers een belangrijke parameter van de plotse klinische verslechtering die een klein deel van de COVID-19-patiënten ongeveer tussen dag 5 tot 10 van ziekzijn meemaakt. Hoe gemakkelijk is het dan om alle patiënten die thuis hun SARS-CoV-2-infectie doormaken te voorzien van een zuurstofsaturatiemeter, zodat ze dit moment door middel van zelfmeting tijdig (eerder) kunnen ontdekken? Want patiënten en huisartsen lijken deze saturatiedip pas laat op te merken, dikwijls pas als de zuurstofsaturatie al gevaarlijk laag is, rond de $90 \%$ of nog lager. Dit fenomeen wordt eufemistisch wel happy hypoxemia genoemd en lijkt haast pathognomonisch voor COVID-19. ' Zo bleek in een Frans onderzoek dat twee derde van de 1712 opgenomen COVID-19-patiënten geen kortademigheid ervaarde, terwijl bijna de helft van hen een te laag zuurstofgehalte had. Het is overigens beter te spreken van 'stille hypoxemie', temeer omdat dit fenomeen met een slechte prognose gepaard gaat: $33 \%$ van de patiënten moest uiteindelijk naar de IC en $26 \%$ overleed in het ziekenhuis. ${ }^{2}$

Op verschillende plaatsen in het land schaften huisartsen al saturatiemeters aan, die ze nu uitlenen aan patiënten met COVID-19. Of ze adviseerden hun patiënten zelf een saturatiemeter te bestellen en te gebruiken zolang ze ziek zijn. Ook enkele lokale huisartsenorganisaties omarmden het idee en rollen het inmiddels uit in hun regio. Het lijkt al bijna 'reguliere huisartsenzorg'. Zeker nu we aan de vooravond van een derde COVID-19-golf staan, met wederom de verwachting dat de druk op de ziekenhuisbeddencapaciteit fors zal toenemen, is het een aantrekkelijke gedachte dat vroeg detecteren van verslechtering en

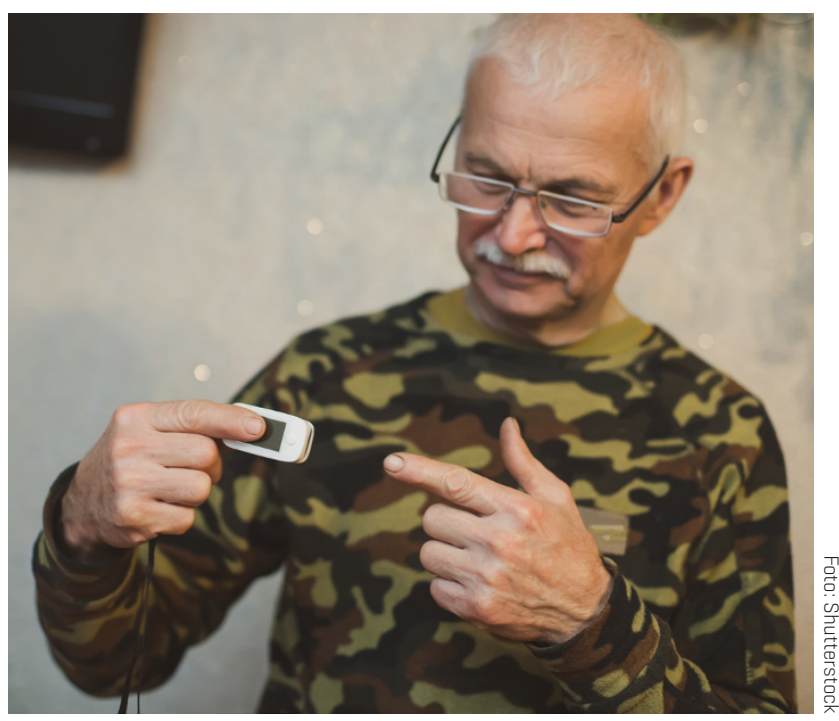

Consumentenmeters zijn niet gevalideerd voor medisch gebruik en daarmee ongeschikt voor thuismonitoring.

snel starten met behandelen een vlotter herstel bevordert. Behalve dat veilige thuismeting verwijzen adequater kan maken, zouden patiënten met COVID-19 van wie de zuurstofsaturatie stabiel blijkt er ook veilig door thuis kunnen verblijven. Bovendien maakt veilige thuismeting van zuurstofsaturatie een vervolgstap mogelijk waarmee de druk op de ziekenhuizen verminderd kan worden. Patiënten met COVID-19 die thuis milde hypoxemie ontwikkelen zouden - in nauw overleg met de tweede lijn - immers thuis zuurstofbehandeling kunnen krijgen, al dan niet in combinatie met dexamethason.

Tot zover de ideeën.

De vraag is of we nu al voldoende argumenten in handen hebben om deze praktijk tot reguliere zorg te verklaren. En of we zonder enige vorm van wetenschappelijke evaluatie een diagnostische en misschien later een daaraan gekop- 
pelde therapeutische strategie kunnen uitrollen. Er zijn volgens ons nog wel wat problemen die om een oplossing vragen.

\section{ZIJN DE METERS WEL GOED?}

Om te beginnen: hoe zit het met de prestaties van de percutane saturatiemeters zelf? Veel meters op de consumentenmarkt zijn niet gevalideerd en volgens de bijsluiter niet geschikt voor medisch gebruik. Ook de onlangs met veel fanfare gepresenteerde Apple Watch 6 niet. In Huisarts en Wetenschap verscheen onlangs een artikel dat - op basis van een validatieonderzoek uit Annals of Family Medicine - concludeerde dat 'consumentenmeters' goed presteren., Dit artikel laat echter belangrijke kanttekeningen onbelicht. Zo toont het betreffende onderzoek op het oog aan dat de onderzochte consumentenmeters prachtige negatief voorspellende waarden hebben, afgezet tegen de referentietest van arterieel gemeten zuurstofspanning of via een gevalideerde percutane saturatiemeter. De sensitiviteit is met $80 \%$ echter laag.

Dat de negatief voorspellende waarde hoog was (99,6\%), komt doordat in het onderzoek (60 deelnemers) slechts bij 15 van de 669 metingen sprake was van een saturatie beneden de $90 \%$. Met andere woorden, zelfs als de hypoxemie bij al deze patiënten gemist zou zijn, dan nog zou de negatief voorspellende waarde van de consumentenmeters hoog zijn (97,8\%). Bij saturatiemeters is het echter belangrijk dat ze veilig zijn, en dat de sensitiviteit dus zo hoog mogelijk is. Je wilt immers liefst bij niemand denken dat de zuurstofspanning goed is wanneer die in werkelijkheid levensbedreigend laag is. In het aangehaalde onderzoek gaf de geteste consumentenmeter in geval van arteriële hypoxemie bij 3 van de 15 metingen (20\%) een goede zuurstofsaturatie aan. Eén op de 5 - dat is onveilig veel als je, zoals bij COVID-19-patiënten, de meters juist vooral meegeeft om te lage zuurstofsaturatiewaarden vroeg te detecteren.

Afgaand op de beperkte literatuur hierover en deze kernreferentie moeten we ervan uitgaan dat consumentenmeters niet veilig doen wat je hoopt dat ze doen, namelijk bij mensen met een te lage zuurstofsaturatie adequaat de waarden 'oppikken',3,5 We vinden daarom dat thuismeting in de praktijk alleen te verantwoorden is met medisch gevalideerde saturatiemeters die getest en goed bevonden zijn. De FDA stelt als goedkeuringseis dat de saturatiemeters in het hele bereik van 70-100\% minder dan 3\% afwijken van de tegelijkertijd arterieel gemeten zuurstofsaturatie. ${ }^{6}$ Daarbij krijgen proefpersonen kunstmatig opgewekte gestandaardiseerde lucht met afnemende
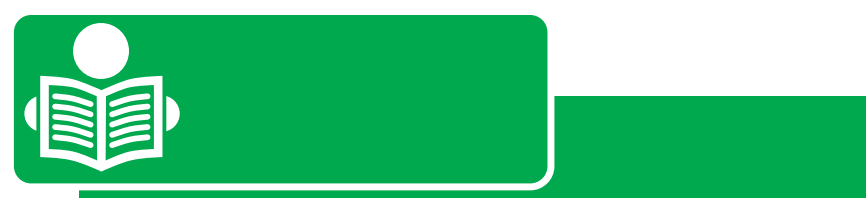

Lees ook: Smit K. Nieuw onderzoek naar thuis zuurstofsaturatie meten bij COVID-19-patiënten. Huisarts Wet 2021;64[4]:75. D0I:10.1007/s12445021-1070-x zuurstofspanning toegediend en wordt gelijktijdig pulsoximetrie en arteriële zuurstofmeting verricht.

Maar zelfs bij meters die aan deze meettechnische eisen voldoen (zogenaamde 'voor medisch gebruik gevalideerde' saturatiemeters) is wetenschappelijke evaluatie van het gebruik in de dagelijkse klinische praktijk gewenst. De vraag is namelijk wat de toegevoegde waarde is van zulke relatief kostbare apparaten boven op de huidige reguliere huisartsgeneeskundige zorg. Daarbij moet je niet alleen rekening houden met alle problemen, weerstand en indirecte effecten, maar ook nagaan wat thuismeting en instructies daarover betekenen voor de besluitvorming van patiënten en dokters. En je zult ook het werkelijke effect op de zorgvraag moeten meten. Die zorgvraag zou immers ten onrechte kunnen afnemen omdat het meten bij patiënten tot schijnveiligheid kan leiden (de zuurstofsaturatie kan nog best goed zijn, terwijl de patiënt mogelijk klinisch slecht is). De zorgvraag kan ook toenemen doordat vaak meten mensen angstig kan maken - zeker wanneer de zuurstofsaturatiewaarden schommelen.

\section{DEGELIJKE ONDERBOUWING ONTBREEKT NOG}

Zuurstofsaturatiemeting thuis bij COVID-19-patiënten is (nog) geen reguliere huisartsenzorg. Op dit moment is er volgens ons onvoldoende zekerheid over de effecten van thuismeting met saturatiemeters. Wel is duidelijk dat consumentenmeters niet gevalideerd zijn voor medisch gebruik en daarmee niet geschikt zijn voor thuismonitoring. Ze presteren bij lage zuurstofsaturatiewaarden simpelweg niet goed genoeg. Onderbouwing van valide thuismonitoring van zuurstofsaturatiemeting is bovendien een cruciale voorwaarde om uitvoering van een volgend praktijkidee binnen een wetenschappelijk kader mogelijk te maken: thuisbehandeling van ernstig zieke COVID-19-patiënten met zuurstoftherapie en eventueel dexamethason. Een degelijke onderbouwing van onze reguliere huisartsenzorg is een groot goed, ook in tijden van crisis.

\section{LITERATUUR}

De literatuurlijst staat bij dit artikel op www.henw.org.

Zwart DLM, Venekamp RP, Smit K, Geersing GJ, Kalkman CJ, Rutten FH. Nu thuismeting van zuurstofsaturatie ineens reguliere huisartsenzorg lijkt te zijn... Huisarts Wet 2021;64[4]:43-4. D0l:10.1007/s12445021-1084-4.

UMC Utrecht, Julius Centrum voor gezondheidswetenschappen en eerstelijnsgeneeskunde, Utrecht: dr. D.L.M. Zwart, huisarts-onderzoeker, d.zwart@umcutrecht.nl; dr. R.P. Venekamp, huisarts-onderzoeker; K. Smit, aios; dr. G.J. Geersing, huisarts-onderzoeker; prof. dr. F.H. Rutten, hoogleraar huisartsgeneeskunde. Afdeling Anesthesiologie, Divisie Vitale functies: prof. dr. C.J. Kalkman, hoogleraar anesthesiologie. Mogelijke belangenverstrengeling: C. Kalkman leidt vanuit het UMC Utrecht een EU Horizon 2020 gefinancierd 'precommercial procurement'-project waarin samen met de industrie wordt gewerkt aan de ontwikkeling van systemen voor draadloze patiëntenmonitoring. Bij geen van de deelnemende bedrijven heeft de auteur een persoonlijk financieel belang 